\title{
Neonatal cholestasis: recent insights
}

\author{
Ramy Mohamed Ghazy ${ }^{1 *}$ (i) and Mohamed Ahmed Khedr ${ }^{2}$
}

\begin{abstract}
Background: Neonatal physiological jaundice is a common benign condition that rarely extends behind the second week of life; however, it may interfere with the diagnosis of a pathological condition termed neonatal cholestasis (NC). The latter is a critical, uncommon problem characterized by conjugated hyperbilirubinaemia. This review aims to highlight the differences between physiological and pathological jaundice, identify different causes of NC, and provide a recent approach to diagnosis and management of this serious condition.
\end{abstract}

Main text: NC affects $1 / 2500$ live births, resulting in life-threatening complications due to associated hepatobiliary or metabolic abnormalities. NC is rarely benign and indicates the presence of severe underlying disease. If jaundice extends more than 14 days in full-term infants or 21 days in preterm infants, the serum bilirubin level fractionated into conjugated (direct) and unconjugated (indirect) bilirubin should be measured. A stepwise diagnostic approach starts with obtaining a complete history, and a physical examination which are valuable for the rapid diagnosis of the underlying disease. The most frequently diagnosed causes of NC are biliary atresia (BA) and idiopathic neonatal hepatitis (INH). The early diagnosis of NC ensures more accurate management and better prognosis. Despite the unavailability of any specific treatments for some causes of NC, the patient can benefit from nutritional management and early medical intervention. Future research should attempt to shed light on methods of screening for NC, especially for causes that can be effectively treated either through proper nutritional support, appropriate chemotherapeutic management, or timely surgical intervention.

Conclusion: Further attention should be paid for diagnosis and treatment of NC as it may be misdiagnosed as physiological jaundice; this may delay the proper management of the underlying diseases and aggravates its complications.

Keywords: Biliary atresia, Neonatal cholestasis, Management of jaundice, Physiological jaundice, Surgical causes of neonatal jaundice

\section{Highlights}

- Definition of neonatal cholestasis.

- Points of differentiation between physiological and pathological jaundice.

- Causes of neonatal cholestasis.

- Recent approach to diagnosis and management of neonatal cholestasis

\section{Background}

Neonatal physiological jaundice is a common benign condition that rarely extends behind the second week of life; unfortunately, it may delay the diagnosis of a

\footnotetext{
* Correspondence: ramysarah@alexu.edu.eg

${ }^{1}$ High Institute of Public Health, Alexandria University, 65 Garidet St., El

Horeya Rd., El Shatby, Alexandria, Egypt

Full list of author information is available at the end of the article
}

pathological condition termed neonatal cholestasis (NC). The latter is a life-threatening, infrequent problem characterized by conjugated hyperbilirubinaemia. In many diseases associated with $\mathrm{NC}$, multiple organs and body systems may be affected, and early intervention may significantly affect the outcome [1]. If jaundice extends more than 2 weeks in full-term infants or 3 weeks in preterm infants, the serum bilirubin level should be fractionated into conjugated and unconjugated bilirubin to exclude the diagnosis of NC [2].

In this review, I will highlight the main differences between physiological and pathological jaundice, identify different reasons of $\mathrm{NC}$ and provide a recent approach to diagnosis and management of many causes of $\mathrm{NC}$.

$\mathrm{NC}$ is considered when the conjugated bilirubin level exceeds $1 \mathrm{mg} / \mathrm{dL}$ with a total bilirubin level $\leq 5 \mathrm{mg} / \mathrm{dL}$ or when the conjugated bilirubin is $\geq 20 \%$ of the total 
bilirubin that is $>5 \mathrm{mg} / \mathrm{dL}$. It is crucial to detect and refer patients with $\mathrm{NC}$ to specialized medical centres to improve their management and prognosis [3].

\section{Epidemiology}

Globally, NC affects $1 / 2500$ live births, and this incidence rate has remained steady from 1985 to 2017. Biliary atresia (BA) and idiopathic neonatal hepatitis (INH) are the most frequently diagnosed aetiologies [4].

\section{Clinical presentation}

Neonates may have immature bile acid excretion, resulting in a state of cholestasis [5]. This state may extend for the first 6 months of infancy, with increased vulnerability to other cholestatic agents. This fact makes NC is atypical feature of neonatal liver disease rather than a late manifestation [6]. $\mathrm{NC}$ is suspected when there is a prolongation of jaundice, necessitating further work-up for cholestasis [7]. Patients' complaints are usually related to fat-soluble vitamin insufficiency, i.e. prolonged prothrombin time. Clinical findings include related to the associated diseases, i.e. cardiac lesions in the case of Alagille syndrome.

\section{Causes}

Any factor that impedes the bile flow from the hepatocytes to the sphincter of Oddi results in a state of cholestasis [8]. NC can be due to either intra/extra-hepatic bile duct (IHBD/EHBD) obstruction or hepatocellular disease (defects in membrane transport, embryogenesis, or metabolic dysfunctions) [7]. Aetiologies of NC can be further divided into those that are surgically correctable and those that are not (Fig. 1).

\section{Surgically correctable aetiologies Biliary atresia}

$\mathrm{BA}$ is the most common cause of liver transplantation (LT) in paediatric patients and needs urgent management to prevent liver cirrhosis. BA is a unique disease to the neonatal period representing the end result of a damaging inflammatory process with unclear aetiology affecting both intra- and extrahepatic bile ducts [9]. Incidence of BA varies worldwide ranging from about 1 in 5-10,000 live births in Japan, China and Taiwan to about 1 in 15-20,000 in Europe [10, 11]. Four different variants of $\mathrm{BA}$ can be distinguished based on clinical or laboratory features: isolated disease, cystic BA, virally associated BA especially with cytomegalovirus infection, and BA with splenic malformation syndrome. While the aetiology of BA is not fully understood with many interesting possibilities for different clinical patterns, $\mathrm{NC}$ is the key feature of BA especially when associated with pale stool and dark urine in a healthy infant.
The biochemical features of the disease include direct hyperbilirubinaemia, raised liver transaminases, raised alkaline phosphatase and $\gamma$-glutamyl transpeptidase; however, these findings may overlap with many other causes of NC. Non-dilatation of biliary tract, absent or non-contractile gallbladder, positive triangular cord and sub-capsular hepatic flow, and right hepatic hypertrophy are the main findings by abdominal ultrasound that help in the diagnosis of BA [12]. The presence of bile duct proliferation, bile plug, a small cell infiltrate, and portal fibrosis and the absence of sinusoidal fibrosis and giant cells are the major histopathological findings in BA [13].

Duodenal aspiration and analysis for bile have been used for diagnosis of BA. Because of the poor differentiating rule of technetium-labelled iminodiacetic acid derivatives, this technique now is less commonly used. Endoscopic retrograde cholangiopancreatography is another recent tool for diagnosis of BA, but it highly invasive. On-table cholangiography remains the gold standard for diagnosis [14].

The usual management of BA is a surgical attempt to restore bile flow using the Kasai portoenterostomy (KPE) technique. The aim of KPE is to restore, albeit imperfectly, the residual intrahepatic biliary system with the gastrointestinal tract and delay the progress to liver fibrosis. In case of failure of KPE, LT should be considered [15].

\section{Choledochal malformation (choledochal cyst [CC])}

$\mathrm{CC}$ is a congenital dilation of the biliary tree not secondary to an obstruction. It is a benign condition but can be complicated by cholestasis, cholelithiasis, cholangitis, biliary cirrhosis, pancreatitis, and malignant transformation [16]. Females are four times as likely as males to experience CC [17]. The flux of pancreatic enzymes into the biliary tree is observed in one third to two thirds of patients due to anomalies in the pancreaticobiliary duct. Biliary epithelium exposure to these caustic enzymes may contribute to CC formation [18]. Abdominal pain, $\mathrm{NC}$, and right upper quadrant mass are the classic presentation [19]. CC is classified as follows: type I, fusiform dilatations of the common bile duct (CBD); type II, true diverticula of the CBD; type III CC (choledochoceles), intraduodenal dilations of the common channel; type IVA CC, multiple IHBD/EHBD dilatations; type IVB CC, EHBD dilatation; and type V CC (Caroli's disease), cystic dilation of the IHBDs [20]. Abdominal ultrasound demonstrates abnormal dilatation of the CBD. Laboratory results reveal conjugated hyperbilirubinaemia, increased $\gamma$-glutamyl transpeptidase (GGT) level, and mild elevation of liver transaminase levels. Albumin and globulin levels are normal. It is essential to differentiate $C C$ from cystic BA, and approximately one tenth of BA patients may have cystic components of EHBDs [21, 22]. Before 


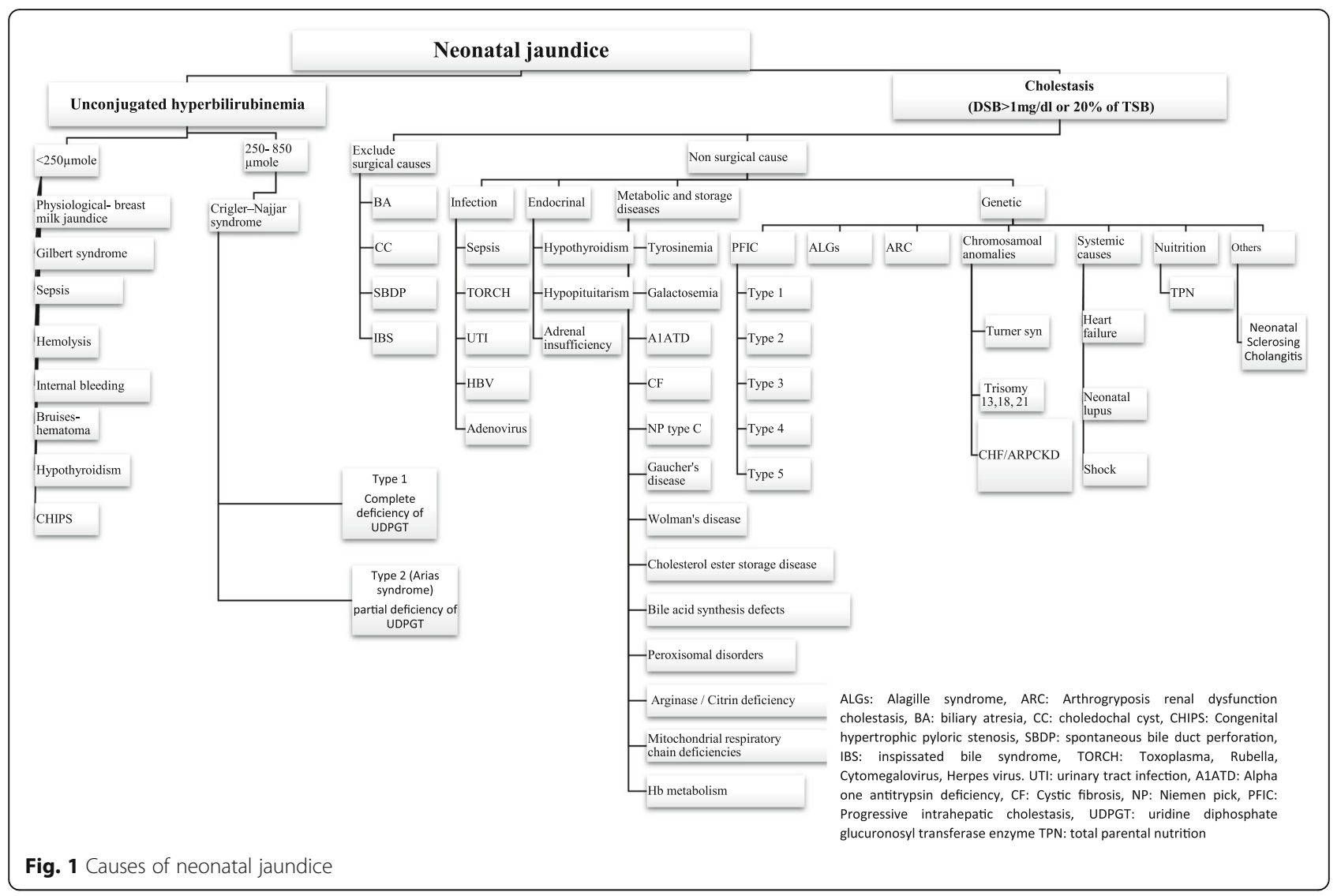

surgical intervention, the precise diagnosis should be reached, as this can affect the management strategy and prognosis [23]. Intraoperative cholangiogram and pathologic examination (absence of an epithelial lining and presence of a grossly visible inner cyst wall) can effectively differentiate between both entities [24, 25]. Surgical cyst excision is the treatment of choice [20]. Laparoscopic hepaticojejunostomy is a new feasible treatment option achieving a better outcome than traditional treatment modalities with fewer complications [26].

\section{Inspissated bile syndrome (IBS)}

IBS is a rare cause of $\mathrm{NC}$ resulting from the obstruction of the EHBDs by either bile plugs or sludge without chemical defects of the bile, anatomical abnormalities, or liver cell damage [27]. IBS accounts for $8 \%$ of the surgically treatable causes of $\mathrm{NC}$, with an estimated incidence of $1 / 175,000$ live births $[28,29]$. Systemic infection, haemolysis, total parental nutrition (TPN), rapid weight loss, progressive familial intrahepatic cholestasis (PFIC), citrin deficiency, and drugs (ceftriaxone) can cause IBS [30]. IBS can resolve spontaneously with or without the administration of oral ursodeoxycholic acid (UDCA) $(10-20 \mathrm{mg} / \mathrm{kg})$. Failed medical management indicates the need for endoscopic retrograde cholangiopancreatography, percutaneous transhepatic cholangiography, or irrigation of the biliary tree with saline or a mucolytic agent through a cholecystostomy $[30,31]$. Co-administration of $\mathrm{N}$-acetylcysteine and glucagon can effectively treat IBS [32]. Omega-three polyunsaturated fatty acids $(500 \mathrm{mg}$ four times per day) can be used as an alternative to surgical intervention [27].

\section{Spontaneous biliary duct perforation (SBDP)}

SBDP is a rare disease involving the perforation of the bile ducts and gallbladder in the absence of $\mathrm{CC}$, and it is commonly diagnosed in early infancy [33]. SBDP occurs at the confluence of the cystic and common hepatic ducts. The cause is mainly idiopathic, although some cases are associated with pancreaticobiliary malunion or distal CBD obstruction by either stones or atresia. Based on the site of perforation, most perforations are situated anteriorly (at the junction of the cystic duct and the CBD) and can be controlled by adjacent structures. If that control fails, bile leaks into the peritoneal cavity, resulting in bilious ascites [34, 35]. Clinically, patients complain of abdominal distension, vomiting, discoloration of hydroceles or hernia sacs, NC, and claycoloured stool. Patients are usually healthy despite the presence of bilious ascites unless there is an associated infection. Persistent vomiting may be the only symptom 
of posterior perforation. Less commonly, there is an acute deterioration associated with sudden abdominal pain, abdominal distension, fever, and vomiting [30].

SBDP can be treated conservatively with broad-spectrum antibiotics [36], endoscopic retrograde pancreatography [34], and percutaneous transhepatic cholangiography [37]. Failed conservative therapy indicates the need for surgical intervention (biliary intestinal reconstruction) [38]. Although SBDP has a good prognosis, it may be complicated by biliary fistulas or portal vein thrombosis [38, 39].

\section{Non-surgical causes}

\section{Idiopathic neonatal hepatitis (INH)}

INH is a term historically applied to infants presenting with idiopathic NC or neonatal hepatitis. There is an increasing number of identified aetiologies producing neonatal hepatitis or cholestasis including infectious and metabolic causes such as tyrosinemia, alpha-1 antitrypsin deficiency (A1ATD), and galactosemia [6]. INH represents $15 \%$ of the causes of $\mathrm{NC}$, characterized histologically by the presence of giant cells and prolonged idiopathic intrahepatic cholestasis. Immature hepatocyte injury caused by infection, biliary obstruction, or metabolic disease results in multinucleated giant cell generation [40]. In addition to the elevated levels of GGT and alkaline phosphatase among BA patients, anti-smooth muscle antibodies are new biomarkers that are useful in differentiating between BA and INH. The antibody levels are significantly higher in patients with BA than in those with INH [41].

\section{Infection}

Sepsis Inflammatory mediators (i.e. bacterial endotoxin and lipopolysaccharides) cause $\mathrm{NC}$ by triggering the release of cytokines [42]. $\mathrm{NC}$ is considered to be a severe condition that may complicate neonatal septicaemia. Prolonged NC will aggravate liver dysfunction, leading to liver failure and the failure of other organs. Management of neonatal sepsis-associated $\mathrm{NC}$ at the early stage is mandatory to prevent its sequelae and maintain normal growth and development [43].

Infection Infection (toxoplasma, rubella, cytomegalovirus, and herpes simplex virus types 1 and 2 ) is an aetiological factor for NC, including BA $[9,44]$. TORCH IgM antibodies were detected in $8.5 \%$ of patients with $\mathrm{BA}$ and in $23 \%$ of the non-BA group; cytomegalovirus is the most commonly diagnosed agent [45].

\section{Metabolic disease}

Alpha one antitrypsin deficiency (A1ATD) Alpha one antitrypsin (ATA) is a glycoprotein synthesized mainly by the liver. ATA is the main protease inhibitor (Pi) [46], protecting against lung damage by inhibiting the neutrophil elastase enzyme [47]. A1ATD is among the most common Mendelian hereditary liver disease in Caucasians, affecting 1/1800 live births [48]. Although A1ATD is a common disorder, it is underdiagnosed, especially in patients with liver disease [49].

In paediatric patients, $\mathrm{BA}$ is generally the most common indication for LT, and A1ATD is the most frequently identified genetic cause [47]. Among the known genetic variants (>100), approximately 30 alleles have clinical implications [50]. The PiM gene is the normal gene; $\mathrm{PiS}$ and $\mathrm{Piz}$ are the most common deleterious genes $[50,51]$. Abnormal proteins accumulate in hepatocytes, inducing hepatitis, hepatic fibrosis, and cirrhosis [52]. A1ATD should be considered when examining infants with NC. Genotyping is recommended irrespective of the serum A1AT concentration [53].

Galactosemia The process of galactose metabolism is illustrated in Fig. 2 [54]. Classic galactosemia is an autosomal recessive disorder [55] affecting 1/16,000-60,000 live births [56]. It presents during the neonatal period and is a potentially lethal disorder that can lead to chronically debilitating complications [57].

Clinically, patients are asymptomatic at birth; after a few days of galactose ingestion, they develop poor feeding, weight loss, vomiting, diarrhea, lethargy, malnutrition, failure to thrive (FTT) (the most common), and hypotonia. Untreated patients may develop hepatocellular damage, NC, severe hemolysis, and cataracts. Advanced cases develop life-threatening conditions, i.e. acute neonatal toxicity syndrome characterized by hypoglycemia, food intolerance, NC, hepatosplenomegaly, hepatocellular insufficiency, renal tubular dysfunction, hypotonia, and sepsis especially with gram-negative organism (E. coli is the commonest), pseudotumour cerebri with bulging fontanel, progressive liver disease, mental retardation, and ovarian failure $[58,59]$.

Reducing substances in urine that do not react with glucose oxidase as a method of newborn screening (NBS) can be an initial test; however, it is not totally valid [60]. High levels of red blood cell galactose 1 phosphate and/or galactitol (detected even after galactose restriction) in the blood and/or urine are more specific. Diagnosis should not be based mainly on elevated galactose 1 phosphate levels [>10 $\mathrm{mg} / \mathrm{dl}$ ], as in benign variants, patients have a normal level [61]. The levels of galactose 1 phosphate should be measured 3 and 9 months after dietary restriction, and then yearly [62]. High urinary and serum galactitol levels are detected even after galactose restriction [63]. Low levels of red blood cell galactose-1-phosphate uridyltransferase (GALT) activity ( $\leq 10 \%$ of control activity) are diagnostic 


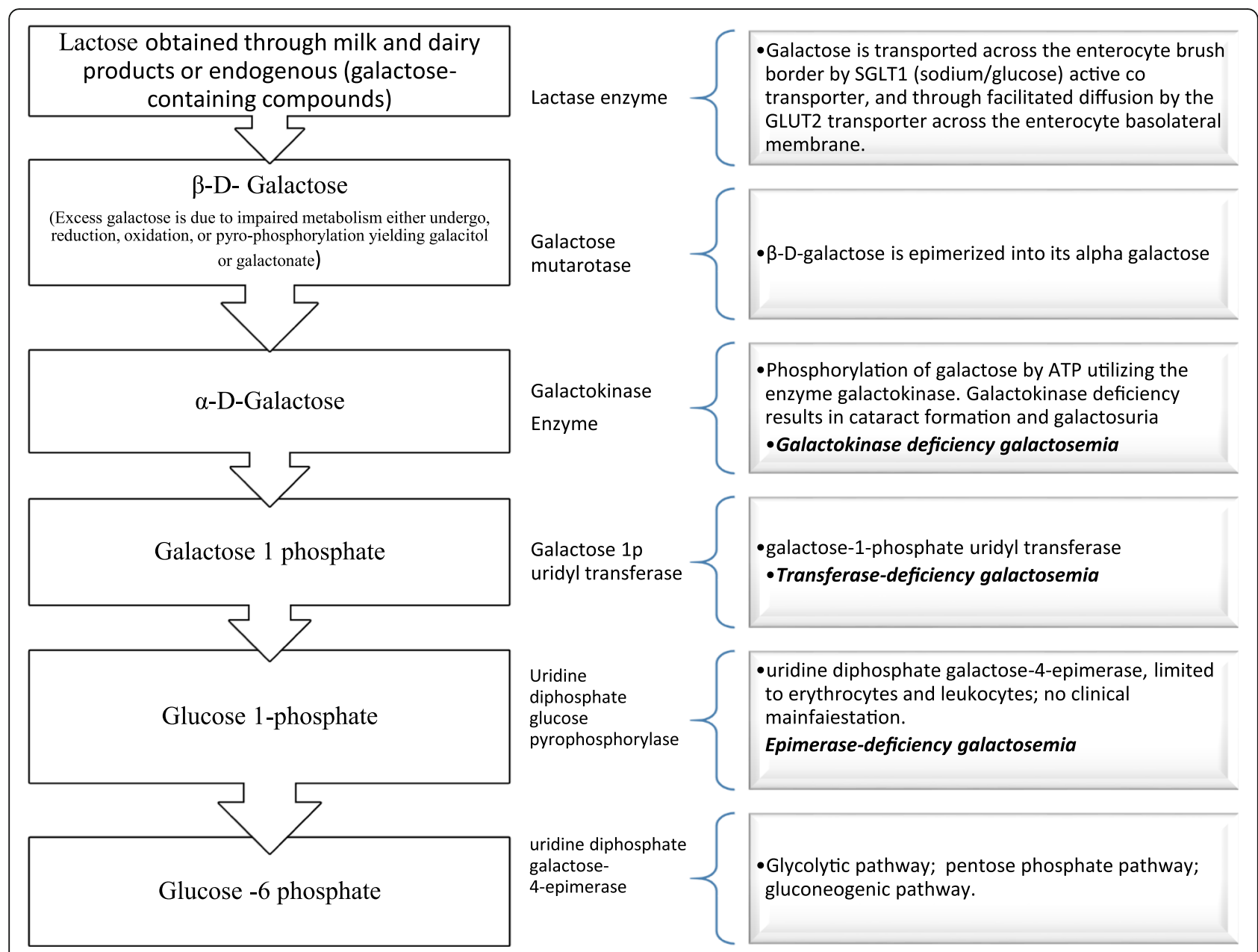

Fig. 2 Galactose metabolism and the effect of enzyme defect on its metabolism

for galactosemia. A negative result does not exclude the disease, and full gene sequencing may be required [64]. GALT mutational analysis has been used in some NBS programmes to improve screening outcome [65]. A lifelong dietary lactose-free diet is the mainstay of treatment; however, this diet may be insufficient to prevent long-term sequelae [66]. Dietary restriction should be started even before confirming the diagnosis, and calcium and vitamin D should be supplemented. A galactose-free diet results in reversal of the acute symptoms and normal growth, with complete recovery of liver function. However, long-term sequelae such as speech impairments may persist into adulthood $[62,67]$. The administration of an aldose reductase inhibitor is another treatment option because galactitol is an important pathogenic metabolite [68], but its role may be less efficient in galactokinase deficiency rather than in classical galactosemia [69].

Tyrosinemia I (TYR-1) (hepatorenal tyrosinemia) The process of phenylalanine metabolism is illustrated in
Fig. 3 [70]. Tyrosinemia (type 1-III) is an autosomal recessive disease associated with a high level of blood tyrosine [71]. The three types of the disease differ genetically, enzymatically, and clinically, and TYR-1associated liver dysfunction is a useful differentiating point [72]. TYR-1 results in symptoms before the second year of life; however, acute liver and renal dysfunction may manifest earlier [73]. Some patients present after their second birthday with isolated coagulopathy or other signs of liver dysfunction, renal tubular dysfunction, hypophosphatemic rickets, and FTT. Moreover, succinyl acetone inhibits aminolevulinate dehydratase, which causes bouts of abdominal pain, polyneuropathy, an increase in $\delta$-aminolaevulinic acid in the urine, and other manifestations resembling acute intermittent porphyria [74]. Neurologic crises, manifesting as painful episodes affecting extremities and/or abdomen, accompanied by hypertension and hyponatremia, may present at any time and may result in respiratory failure and death [75]. Survivors may develop hepatomas that often transition to hepatocellular carcinoma (HCC), with a 


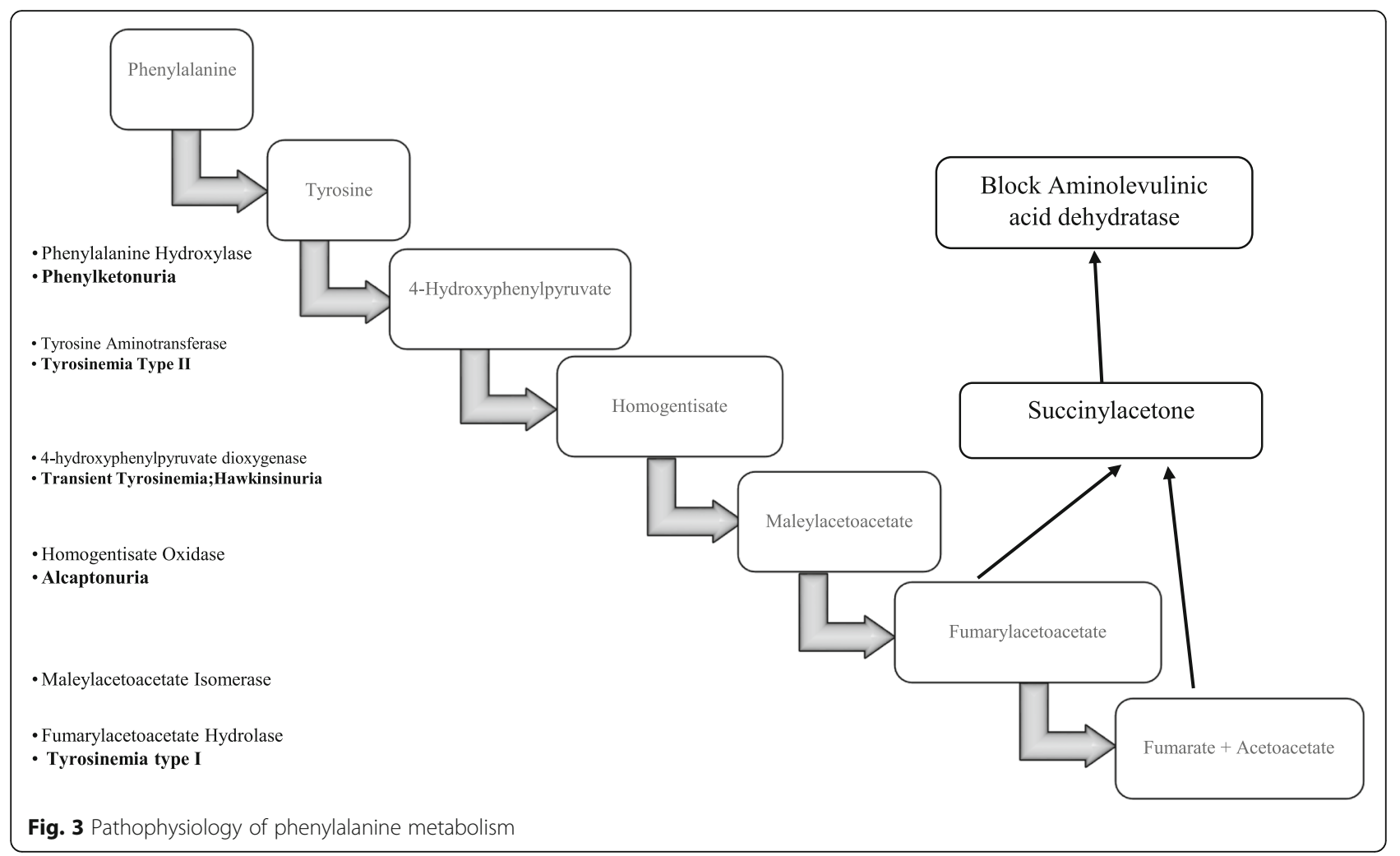

lifetime risk as high as 37\% [76]. HCC may be the first recognized clinical event [77]. Newborns referred to metabolic centres for elevated tyrosine and/or succinyl acetone levels suspected of having TYR-1 should receive clinical and laboratory evaluations as soon as possible. NBS using blood/urinary succinyl acetone levels is predicted to identify all affected infants [78]. Plasma amino acids and liver function tests, including the prothrombin time, should be investigated. Patients should restrict their tyrosine and phenylalanine intake to maintain their plasma levels within the non-harmful range [73]. This prevents corneal tyrosine crystal formation. If the blood concentration of phenylalanine becomes too low $(<$ $20 \mu \mathrm{mol} / \mathrm{L}$ ), additional natural protein should be added to the diet [79]. Early treatment with nitisinone is associated with lower rates of LT, without any improvement in the neurological complications [80]. LT, as a treatment for TYR-1, is limited to patients who have developed malignancies or decompensated liver disease and in those who do not have access to or are refractory to nitisinone [81]. Successful LT is expected to restore liver function and reduce the risk of HCC [82].

Citrin deficiency Mutation of the human SLC25A13 gene encoding a mitochondrial aspartate/glutamate carrier isoform 2 can lead to its deficiency. The deficiency of this carrier results in neonatal intrahepatic cholestasis caused by citrin deficiency (NICCD), FTT, dyslipidaemia (intermediate phenotype), and adult-onset fatal disease, namely, citrullinemia type II [83]. NICCD manifests early in infancy with NC, diffuse fatty liver, parenchymal cellular infiltration associated with hepatic fibrosis, hypoalbuminemia, coagulopathy, liver dysfunction with or without hypoglycaemia, and galactosemia. Citrulline levels are elevated in the early neonatal period, followed by increases in the levels of arginine, threonine, methionine, phenylalanine, tyrosine, and galactose [84-86]. The prevalence of NICCD is underestimated because of the majority of the affected infants die early or are misdiagnosed as having INH [85]. DNA analysis or Western blot analysis of defective proteins in lymphocytes are the most reliable diagnostic tools [87]. Dietary supplementation with a lactose-free formula, a medium- chain triglyceride-enriched formula, fat-soluble vitamins, UDCA, and phenobarbital is strongly recommended. LT is another treatment option in cases of medical treatment failure [84].

Cystic fibrosis (CF) $\mathrm{CF}$ is an autosomal recessive disease that results from a mutation in the CF transmembrane regulator (CFTR) [88]. Recently, a novel mutation of CF, c. $3871 \mathrm{G}>\mathrm{T}$, was identified [89]. Classic CF manifests with pulmonary symptoms, meconium ileus, recurrent pancreatitis or pancreatic insufficiency, and focal biliary cirrhosis due to the obstruction of the IHBDs [90]. NC occurs more frequently in patients with 
meconium ileus and TPN. The associated clay stool and conjugated hyperbilirubinaemia may result in a misdiagnosis of BA [91]. The abnormal expression of CFTR in the apical surface of the biliary epithelium affects bile fluidity and viscosity, resulting in abnormal bile accumulation [92, 93]. NC resolves, on average, by 9.2 months of age; if not, hepatobiliary complications will arise [94].

NBS can be accomplished by measuring the immunoreactive trypsinogen level in dried blood spot. If the result measured $\geq 62 \mathrm{ng} / \mathrm{mL}$, testing for CFTR mutations through DNA sequencing is mandatory. Patients with $\geq$ 2 mutations are affected with the disease, and those with one mutation are diagnosed as carriers. This diagnostic approach had a sensitivity and positive predictive value of $92 \%$ and $34 \%$ respectively [90].

The mainstay of treatment is to delay the progression to cirrhosis and development of portal hypertension. Management of CF should include multi-speciality team, including pulmonologist, hepatologist, otolaryngology specialist, dietitian, radiologist, psychologist, and surgeon.

Poor nutritional intake is a common problem and caused by poor appetite, malabsorption, and increased caloric expenditure. If there is pancreatic insufficiency, evaluation of plasma levels of fat-soluble vitamins after the initiation of enzyme and vitamin supplementation 3-6 months after initiation or change in vitamin therapy and yearly subsequently should be done [95]. For more details on nutritional requirements for cholestatic patient please, read the article at https://www.sciencedirect.com/science/article/pii/S111066381730054X.

Reduction of hyperbilirubinaemia can be achieved either medically (UDCA $20-30 \mathrm{mg} / \mathrm{kg}$ body weight/ day) or by cholangiogram. In addition to its immunoregulatory function, UDCA has a cytoprotective effect against toxic bile acids and it displaces them. Furthermore, UDCA stimulates calcium-activated chloride channels [96].

However, progression to stenosis and fibrosis of the hepatic ducts and CBD may occur, and surgical correction becomes necessary. LT is offered for patients with end-stage liver disease provided that there is any contraindication [93]. LT to treat CF-related liver disease accounted for $3.5 \%$ of all paediatric LTs over a 16 -year period [94].

Bile acid synthesis disorders (BASDs) BASDs are disorders of primary bile acid (cholic and chenodeoxycholic acid) synthesis that result in liver injury due to the accumulated toxic intermediate metabolites. Abnormalities in bile excretion result in the retention of other toxic metabolites within the liver. BASDs should be included in the differential diagnosis of NC [97]. The effects of BASDs on the liver range from persistent cholestasis to acute hepatitis or liver failure. Clinically, patients present with NC, FTT, hepatosplenomegaly, rickets, evidence of fat malabsorption, and bleeding. Neurologic effects include seizures, developmental delay, deafness, blindness, and neuromuscular weakness [98]. UDCA disrupts serum bile acid levels, and liver transaminases are elevated with normal GGT. Urinary bile acids should be measured to identify the synthetic defect. Liver biopsy is not diagnostic [97]. Treatment with cholic acid, not ursodiol, suppresses the production of toxic metabolites and maintains normal growth and development [98].

\section{Genetic causes}

Alagille syndrome (ALGS) (arteriohepatic dysplasia, Alagille-Watson syndrome) is a multisystem autosomal dominant disorder. The majority of cases are caused by the JAG1 gene mutation [99]. NOTCH 1 mutations are diagnosed in $<1 \%$ of the cases, indicating a higher risk of renal disease [100]. ALGS affects the liver, heart, skeleton, eyes, kidneys, and central nervous system, and it leads to characteristic facial features [101]. ALGS is a rare disorder affecting 1/70,000 live births, based on the presence of neonatal liver disease; however, it is underestimated because that metric does not take into account the reduced penetrance of the condition [102]. In newborns, bile duct paucity may be present in conjunction with ductal proliferation, resulting in its misdiagnosis as BA [103]. However, before molecular genetic testing, variable expression can be determined through segregation analysis, and it has been suggested that the presence of only one feature is sufficient to make the diagnosis in extended family members [104] (Fig. 4). ALGS is now defined by both its genotype and its phenotype. Bile duct paucity is not a characteristic of ALGS, but it is present in trisomy 21, CF, congenital infections, A1ATD, and Zellweger and Ivemark syndromes [101]. All patients should undergo liver and renal function tests, lipid profiling, serum bile acids tests, and clotting studies. Ophthalmic examinations, spinal X-rays, abdominal ultrasounds, echocardiographs, scintiscans, and liver biopsies may be needed in ALGS patients to diagnose systemic complications. All patients should undergo regular growth monitoring, receive nutritional support, and have meticulous renal and pancreatic function follow-up [101]. Fortunately, intense pruritus due to associated liver disease can be treated with choleretic agents such as UDCA, cholestyramine, rifampicin, or naltrexone. Biliary diversion is a helpful procedure and can be beneficial before LT. In certain cases, partial external biliary diversion has also been demonstrated to be successful [105]. The success of the LT is affected by the associated comorbidities [106]. 


\section{Suspected ALGS}

Intralobular bile duct paucity on liver biopsy (in full term infants, ratio of bile ducts number of bile ductules to portal tract is $<0.9$ ) + at least three out of five other major clinical features as

follows:

- Cholestasis

- Cardiac disease with peripheral pulmonary stenosis.

- Skeletal anomalies with butterfly thoracic vertebrae

- Posterior embryotoxon

- Characteristic facies
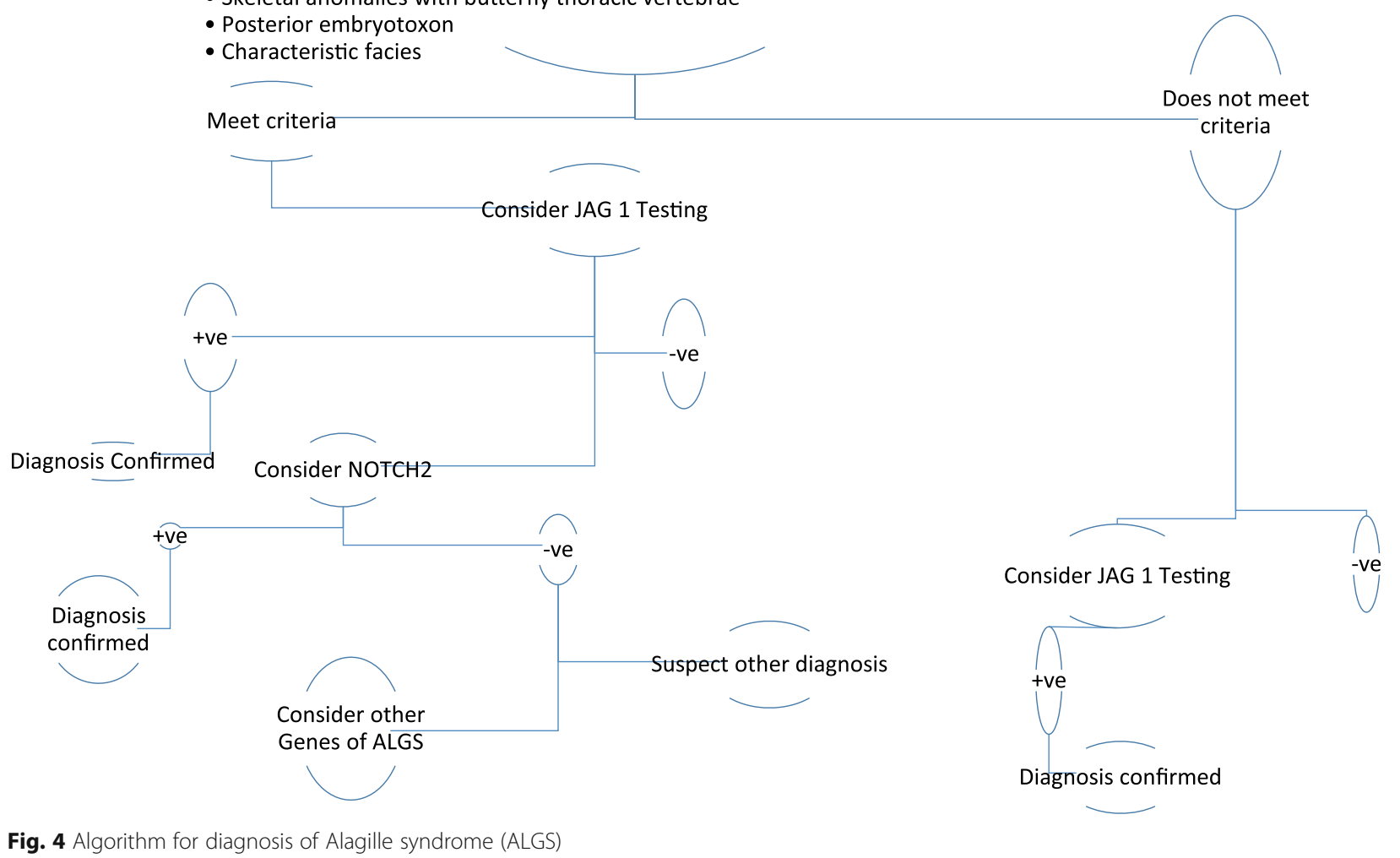

Fig. 4 Algorithm for diagnosis of Alagille syndrome (ALGS)

Progressive familial intrahepatic cholestasis (PFIC) PFIC is a heterogeneous group of rare, autosomal recessive disorders resulting from defects in the mechanisms involved in bile formation with typical clinical, biochemical, and histological features. PFIC presents with intrahepatic cholestasis in infancy or childhood [107]. The worldwide incidence is $1 / 50,000$ to $1 / 100$, 000 , with equal distribution between the sexes [108]. The course of the disease involves portal hypertension, liver failure, cirrhosis, and HCC along with several extra-hepatic manifestations. The five types of PFIC are identified in Table 1 [109, 110].

Arthrogryposis renal dysfunction cholestasis (ARC) syndrome ARC syndrome is a rare fatal autosomal recessive multisystem disorder involving the liver, kidney, skin, central nervous system, and musculoskeletal system; it is caused by mutations in the VPS33B or VIPAR gene [111]. ARC syndrome includes arthrogryposis (muscle atrophy, radial deviation of the wrist, dislocation of both hip joints, flexion contracture of the knee joints, and calcaneo-valgus), renal tubular acidosis, and $\mathrm{NC}$ [112]. Half of the cases have ichthyosis, and one fourth of those with ARC syndrome may have platelet anomalies. Agenesis of the corpus callosum is reported in more than one fifth of cases. One tenth of patients with ARC syndrome have congenital cardiovascular anomalies, deafness, recurrent infections, and internal bleeding due to coagulation dysfunctions. Mild or atypical symptoms may delay diagnosis. The prognosis of ARC syndrome is poor, and the majority of patients die during infancy [113]. The pathogenesis characteristic of ARC syndrome primarily involved degeneration of the anterior motor neurons, whereas the severity of arthrogryposis may be traced to placental insufficiency during pregnancy, with oligohydramnios in the mother and foetal growth restriction. Osteopenia and pathological fractures are attributable to impaired renal tubular reabsorption and secondary hyperparathyroidism [114]. Renal tubular dysfunction manifests in the form of Fanconi syndrome, renal tubular acidosis, nephrogenic diabetes insipidus, glucosuria, aminoaciduria, and phosphaturia [114]. In 
Table 1 Characteristic features of the different types of progressive familial intrahepatic cholestasis [102-104]

\begin{tabular}{|c|c|c|c|c|c|}
\hline Item & PFIC 1 Byler disease & PFIC 2 & PFIC 3 & PFIC 4 & PFIC5 \\
\hline \multicolumn{6}{|c|}{ Both genders are equally affected, incidence $1 / 50000-100,000$} \\
\hline \multicolumn{6}{|l|}{ Genetics } \\
\hline Inheritance & $A R$ & $A R$ & $A R$ & $A R$ & $A R$ \\
\hline Gene & ATP8B1/F1C1 & ABCB11/BSEP & ABCB4/MDR3 & TJP2 & $\mathrm{NR} 1 \mathrm{H} 4$ \\
\hline Protein & $\begin{array}{l}\text { Familial intrahepatic } \\
\text { cholestasis } 1 \text { (FICl) }\end{array}$ & $\begin{array}{l}\text { Bile salt export protein } \\
\text { (BSEP) }\end{array}$ & $\begin{array}{l}\text { Multidrug resistance } \\
\text { protein } 3 \text { (MDR3) }\end{array}$ & TJP2 protein & $\begin{array}{l}\text { FXR, the key } \\
\text { regulator of BS } \\
\text { metabolism }\end{array}$ \\
\hline Chromosome & $18 q 21-q 22$ & $2 q 24$ & $7 q 21$ & $9 q 12$ & $12 q 23.1$ \\
\hline Location & $\begin{array}{l}\text { Wide tissue distribution } \\
\text { including almost all } \\
\text { epithelial cells; on } \\
\text { apical membranes }\end{array}$ & $\begin{array}{l}\text { Hepatocyte canalicular } \\
\text { membrane }\end{array}$ & $\begin{array}{l}\text { Hepatocyte canalicular } \\
\text { membrane }\end{array}$ & Tight junctions & $\begin{array}{l}\text { Bile canaliculi, FXR is } \\
\text { highly expressed in } \\
\text { liver and pancreatic } \\
\beta \text { cells }\end{array}$ \\
\hline \multicolumn{6}{|l|}{ Pathophysiology } \\
\hline $\begin{array}{l}\text { Function of } \\
\text { hereditary } \\
\text { defect }\end{array}$ & $\begin{array}{l}\text { Aminophospholipid } \\
\text { flippase }\end{array}$ & Bile acid secretion & $\begin{array}{l}\text { Phosphatidylcholine } \\
\text { secretion }\end{array}$ & $\begin{array}{l}\text { Integral tight } \\
\text { junction protein } \\
\text { (claudin-1) }\end{array}$ & $\begin{array}{l}\text { Farnesoid } X \\
\text { receptor loss }\end{array}$ \\
\hline \multicolumn{6}{|l|}{ Clinical findings } \\
\hline Age of onset & Neonates & Neonates & 1 month-20 years & $\begin{array}{l}\text { Infancy, } \\
\text { childhood }\end{array}$ & Neonate \\
\hline Course & Progressive & Progressive & Progressive & Progressive & Rapidly progressive \\
\hline Cholestasis & Chronic & Chronic & Chronic & Chronic & Chronic \\
\hline Pruritus & Severe & Severe & Moderate & Severe & Severe \\
\hline Others & $\begin{array}{l}\text { Other features include } \\
\text { short stature, diarrhoea, } \\
\text { hepatosplenomegaly, } \\
\text { malabsorption, } \\
\text { pancreatitis, respiratory } \\
\text { disease, and } \\
\text { occasionally } \\
\text { sensorineural hearing } \\
\text { loss }\end{array}$ & $\begin{array}{l}\text { Growth failure } \\
\text { gallbladder stones }\end{array}$ & $\begin{array}{l}\text { Later onset cholestasis, } \\
\text { portal hypertension, } \\
\text { minimal pruritus, gall } \\
\text { bladder stone, cupper } \\
\text { accumulation in liver } \\
\text { tissue, and increase in } \\
\text { urinary cupper. }\end{array}$ & $\begin{array}{l}\text { Intrahepatic } \\
\text { cholestasis, early } \\
\text { childhood liver } \\
\text { failure, portal } \\
\text { hypertension, } \\
\text { neurological and } \\
\text { respiratory } \\
\text { symptoms }\end{array}$ & $\begin{array}{l}\text { Coagulopathy } \\
\text { a direct } \\
\text { consequence of the } \\
\text { loss of FXR function. } \\
\text { Failure to thrive and } \\
\text { ascites, gallstones } \\
\text { pleural effusions, and } \\
\text { intraventricular } \\
\text { haemorrhage at birth }\end{array}$ \\
\hline
\end{tabular}

Risk of malignancy

Laboratory findings

\begin{tabular}{|c|c|}
\hline Serum GGT & Normal/low \\
\hline Serum ALT & Mildly elevated \\
\hline Serum AFP & Normal \\
\hline $\begin{array}{l}\text { Serum primary bile } \\
\text { acid concentration }\end{array}$ & $\begin{array}{l}\text { Very high + normal } \\
\text { cholesterol }\end{array}$ \\
\hline $\begin{array}{l}\text { Biliary bile acid } \\
\text { secretion }\end{array}$ & Low \\
\hline \multicolumn{2}{|l|}{ _iver biopsy } \\
\hline Histology & $\begin{array}{l}\text { Minimal giant cell } \\
\text { transformation, } \\
\text { intracanalicular } \\
\text { cholestasis, no ductal } \\
\text { proliferation, minimal } \\
\text { inflammation. Late } \\
\text { fibrosis }\end{array}$ \\
\hline
\end{tabular}

$\mathrm{HCC} /$

cholangiocarcinoma

(in 30\% of patients)

Normal/low
$>5 \times$ normal
Elevated
Very high
Low
Giant cell
transformation,
intracanalicular
cholestasis, no
ductular proliferation,
moderate
inflammation, fibrosis,
extramedullary
hemopoiesis

High

$>5 \times$ normal

Normal

High

Low
Giant cell

transformation, intracanalicular cholestasis, ductular proliferation, moderate inflammation, marked fibrosis, lipid crystals within bile ducts, and fibroobliterative bile duct lesions $\mathrm{HCC}$
Normal or mildly Low to normal increased

$\begin{array}{ll}\text { Elevated } & \text { Elevated } \\ \text { Elevated } & \text { Elevated }\end{array}$

Ductular reaction, Intralobular diffuse giant cell cholestasis, transformation, diffuse giant cell and ballooning of transformation, hepatocytes and ballooning intralobular hepatocytes, and cholestasis ductular reaction. Micronodular cirrhosis and fibrosis were evident at 
Table 1 Characteristic features of the different types of progressive familial intrahepatic cholestasis [102-104] (Continued)

\begin{tabular}{|c|c|c|c|c|c|}
\hline Item & PFIC 1 Byler disease & PFIC 2 & PFIC 3 & PFIC 4 & PFIC5 \\
\hline & & & & & later stages \\
\hline Electron microscopy & $\begin{array}{l}\text { Byler type coarsely } \\
\text { granular bile; loss of } \\
\text { microvilli, swollen } \\
\text { microvilli }\end{array}$ & $\begin{array}{l}\text { Amorphous } \\
\text { filamentous } \\
\text { bile; loss } \\
\text { of microvilli }\end{array}$ & $\begin{array}{l}\text { Presence of cholesterol } \\
\text { crystals; } \\
\text { loss of microvilli, bile } \\
\text { is dense and } \\
\text { amorphous. }\end{array}$ & $\begin{array}{l}\text { Elongated tight } \\
\text { junctions } \\
\text { between } \\
\text { adjacent } \\
\text { hepatocytes and } \\
\text { biliary canaliculi } \\
\text { seen on biopsy }\end{array}$ & \\
\hline \multirow{3}{*}{ Immunohistochemistry } & BSEP positive & BSEP negative & BSEP positive & & BSEP negative \\
\hline & MDR3 positive & MDR3 positive & MDR3 negative & & MDR3 positive \\
\hline & GGT negative & $\begin{array}{l}\text { GGT negative to } \\
\text { weakly positive }\end{array}$ & GGT positive & & GGT positive \\
\hline \multicolumn{6}{|l|}{ Treatment } \\
\hline & $\begin{array}{l}\text { UDCA, rifampin } \\
\text { fat-soluble vitamins + biliary } \\
\text { diversion, ileal exclusion, } \\
\text { liver transplantation; } \\
\text { post-orthotropic } \\
\text { liver transplantation } \\
\text { diarrhoea, pancreatitis, } \\
\text { steatorrhea, } \\
\text { fatty liver with } \\
\text { possible progression } \\
\text { to cirrhosis }\end{array}$ & $\begin{array}{l}\text { Biliary diversion, liver } \\
\text { transplantation } \\
\text { (possible recurrent } \\
\text { disease after } \\
\text { transplantation) }\end{array}$ & $\begin{array}{l}\text { UDCA if residual PC } \\
\text { secretion; liver } \\
\text { transplantation }\end{array}$ & $\begin{array}{l}\text { Liver } \\
\text { transplantation }\end{array}$ & Liver transplantation \\
\hline
\end{tabular}

$A R$ autosomal recessive, GGT gamma-glutamyl transferase, AFP alpha fetoprotein, $A L T$ alanine aminotransferase, BSEP bile salt export pump, UDCA ursodeoxycholic acid, HCC hepatocellular carcinoma

the absence of biliary obstruction, patients with hepatomegaly and NC with low GGT levels and normal or slightly elevated liver enzymes are characteristic of ARC. It is recommended that patients with low GGT levels and conjugated hyperbilirubinaemia associated with ichthyosis, deafness, platelet dysfunction, and central nervous system malformations should be tested for VPS33B mutations [115]. A paucity of bile ducts, giant cell transformation, bile plugs or lipofuscin deposition, and portal fibrosis differentiate ARC from BA [116]. At present, there is no specific treatment for ARC syndrome; supportive care includes intravenous fluids, anti-infection measures, and supplementation with UDCA, fat-soluble vitamins, calcium glubionate, Lthyroxine, and phosphate. Nevertheless, immediate orthopaedic intervention for patients with joint contractures, congenital hip dislocations, and a vertical talus may be required. Aggressive orthopaedic management is not recommended because the patient's poor overall status and the low survival rate may affect the outcome of the surgery [117]. In cases of the failure of medical therapy, it is advisable to consider LT to improve severe cholestasis and intractable pruritus [111].

Nutrition: total parenteral nutrition-associated cholestasis (TPN-AC) NC is a frequently reported complication of TPN [6]. TPN-AC is diagnosed if there is persistent conjugated hyperbilirubinaemia greater than $2.0 \mathrm{mg} / \mathrm{dL}$ for at least two consecutive tests during TPN, with the absence of any other causes of NC [118]. The exact aetiology is not known; risk factors associated with TPN-related cholestasis are very low birth weight, prematurity, the duration of TPN, sepsis, the absence of enteral feeding, the quality or quantity of amino acid intake, male sex, trace mineral or phytosterol toxicity, and perinatal depression or shock [119121]. Intestinal resection and its complications have also been associated with the occurrence of TPN-AC [122]. The severity of the disease varies from mild to severe, and it can lead to significant hepatic injury and end-stage liver disease. The histopathological changes are correlated with the duration of TPN $[123,124]$. A shortened TPN course and early initiation of enteral feeding can effectively decrease the frequency of $\mathrm{NC}$. UDCA $(10-30 \mathrm{mg} / \mathrm{kg} /$ day) is the most widely used drug in the treatment of TPN-AC [125].

Wolman's disease Wolman's disease is a fatal autosomal recessive disorder representing the infantile form of lysosomal acid lipase deficiency. Patients usually do not survive beyond infancy. There are two different phenotypes that lie on a clinical continuum, depending on the amount of functional enzyme that is produced in vivo [126]. Clinically, Wolman's disease presents with hepatomegaly, FTT, diarrhoea, vomiting, malabsorption haemophagocytic lymphohistiocytosis, and liver failure 
[127]. The exact disease incidence is unknown but is estimated to be approximately $1 / 500,000$ live births [128]. There is no or very minimal lysosomal acid lipase activity $(<1 \%$ of normal), resulting in heavy accumulation of cholesteryl esters and triglycerides in visceral organs, i.e. liver and bone marrow, which means that patients usually present within the first 2-4 months of life [128, 129]. Adrenal infiltration is leading to necrosis and calcification of the adrenal glands in approximately $50 \%$ of patients. Intestinal involvement results in chronic diarrhoea or steatorrhea secondary to the disease process itself and the resultant severe malabsorption [129]. Oxysterol levels are a new biomarker for the diagnosis of Wolman's disease and are correlated with the clinical management of the disease [130]. Intestinal malabsorption, hepatic impairment, and adrenal insufficiency explain the very poor prognosis of these young patients [131].

\section{Management}

\section{General medical management}

Most children having $\mathrm{NC}$ are malnourished and require an adequate provision of caloric requirements to prevent and treat malnutrition associated with steatorrhea and malabsorption. Affected patients should receive $125 \%$ of the recommended dietary allowance based on ideal body weight [132]. Medium-chain triglyceride oil should be administered in a dose of $1-2 \mathrm{~mL} / \mathrm{kg} / \mathrm{d}$ in $2-4$ divided doses in expressed breast milk. In non-breast feed, a mixture of puffed rice powder and MCT to milk can make feeds energy -dense. Essential fatty acids should constitute $2-3 \%$ of the energy provided. Vegetable protein at $2-3 \mathrm{~g} / \mathrm{kg} / \mathrm{d}$ is recommended. 1,25-Dihydroxyvitamin $\mathrm{D}_{3}$ $(0.05-0.2 \mu \mathrm{g} / \mathrm{kg} / \mathrm{d})$ is recommended in the presence of significant bone changes or patients having severe cholestasis. Vitamin $\mathrm{K}$ is administered at a dose of $5 \mathrm{mg}$ intramuscular, subcutaneously or intravenously, at diagnosis to correct the coagulopathy. Water soluble vitamins are given orally 1-2 times the recommended daily allowance. Vitamin supplementation should be continued till 3 months after resolution of jaundice [133].

\section{Specific treatment}

Special infant formula and diets are recommended for children with specific diagnosis (galactosemia, fructosemia, and tyrosinemia). Treatment with nitisinone $(1 \mathrm{mg} /$ $\mathrm{kg} / \mathrm{d}$ ) in addition to dietary restriction leads to rapid reduction of toxic metabolites in tyrosinemia. Specific therapy is recommended for patients with CMV, herpes, and toxoplasmosis-related NC. Antibiotics need to be administered in patients with bacterial sepsis based on the site of infection and the performed culture. There is no role for steroids in INH.
In infants with pruritus due to severe cholestasis, UDCA $(20 \mathrm{mg} / \mathrm{kg} / \mathrm{d})$, rifampicin $(5-10 \mathrm{mg} / \mathrm{kg} / \mathrm{d})$, and phenobarbitone $(5-10 \mathrm{mg} / \mathrm{kg} / \mathrm{d})$ are drugs of choice. Kasai's operation entails removal of the atretic extrahepatic tissue and a Roux-en-Y jejunal loop anastomosis to the hepatic hilum. Patients' bilirubin normalizes after $\mathrm{KPE}$ if it was performed before the end of the third month [134]. About $20 \%$ of all patients undergoing KPE during infancy survive into adulthood with their native liver [135]. In children with PFIC without decompensated cirrhosis, external and internal biliary diversion has been shown to be of benefit [136].

\section{Liver transplantation}

Liver transplantation is the standard therapy for decompensated cirrhosis due to any cause, and it is now well established. Any baby who has had failed KPE (bilirubin remains $>2 \mathrm{mg} / \mathrm{dL}, 6$ months after surgery) should be referred to a transplant centre.

\section{Conclusion}

NC may be misdiagnosed as physiological jaundice; this may delay the proper management of the underlying disease and aggravates its complications. General practitioner and health care workers should be able to differentiate between physiological jaundice and NC especially BA; consequently, they would refer the affected patients to pediatric hepatologist as early as possible. In addition, parents must know when they should seek medical advice and when to suspect NC.

\section{Abbreviations}

A1ATD: Alpha-1 antitrypsin deficiency; ALGs: Alagille syndrome;

ARC: Arthrogryposis renal dysfunction cholestasis; BA: Biliary atresia; BASDs: Bile acid synthesis disorders; CBD: Common bile duct;

CC: Choledochal cyst; CF: Cystic fibrosis; CFTR: Cystic fibrosis transmembrane regulator; EHBDs: Extra-hepatic bile ducts; FFT: Failure to thrive;

GALT: Galactose-1-phosphate uridyltransferase; GGT: Gamma-glutamyl transpeptidase; HCC: Hepatocellular carcinoma; IHBDs: Intrahepatic bile ducts: INH: Idiopathic neonatal hepatitis; KPE: Kasai portoenterostomy; LT: Liver transplantation; NBS: Newborn screening; NC: Neonatal cholestasis; NICCD: Neonatal intrahepatic cholestasis caused by citrin deficiency; PFIC: Progressive familial intrahepatic cholestasis; TPN: Total parental nutrition; TPN-AC: Total parenteral nutrition-associated cholestasis;

UDCA: Ursodeoxycholic acid

\section{Acknowledgments \\ I would like to thank Dr. Salma Nagy and Dr. Bassam Ayoub for revising this manuscript.}

Authors' contributions

RMG is the author of the manuscript, searched the literature, wrote the manuscript, designed the figure and tables, and finally sent the manuscript for publication. MAK revised the manuscript and wrote the paragraph about "Biliary atresia" section. Both authors read and approved the final manuscript.

Funding

I did not receive any fund for this publication.

Availability of data and materials

All data generated or analysed during this study are included in this published article. 


\section{Ethics approval and consent to participate}

Not applicable

\section{Consent for publication \\ Not applicable}

\section{Competing interests}

The authors declare that they have no competing interests.

\section{Author details}

${ }^{1}$ High Institute of Public Health, Alexandria University, 65 Garidet St., El Horeya Rd., El Shatby, Alexandria, Egypt. ${ }^{2}$ National Liver Institute, Menoufia University, Shibin Al Kawm, Egypt.

\section{Received: 9 July 2019 Accepted: 9 October 2019} Published online: 08 November 2019

\section{References}

1. Hoerning A, Raub S, Dechêne A, Brosch MN, Kathemann S, Hoyer PF et al (2014) Diversity of disorders causing neonatal cholestasis-the experience of a tertiary pediatric center in Germany. Front Pediatr 2:65

2. Hartley J. The jaundiced baby. Atlas of Pediatric Hepatology. Cham: Springer; 2018. p. 1-16

3. Götze T, Blessing H, Grillhösl C, Gerner P, Hoerning A (2015) Neonatal cholestasis-differential diagnoses, current diagnostic procedures, and treatment. Front Pediatr 3:43

4. Moyer V, Freese DK, Whitington PF, Olson AD, Brewer F, Colletti RB et al (2004) Guideline for the evaluation of cholestatic jaundice in infants: recommendations of the North American Society for Pediatric Gastroenterology, Hepatology and Nutrition. J Pediatr Gastroenterol Nut 39(2):115-128

5. Suchy FJ, Balistreri WF, Heubi JE, Searcy JE, Levin RS (1981) Physiologic cholestasis: elevation of the primary serum bile acid concentrations in normal infants. Gastroenterology. 80(5 pt 1):1037-1041

6. Suchy FJ (2004) Neonatal cholestasis. Pediatr Rev 25(11):388-396

7. Fawaz R, Baumann U, Ekong U, Fischler B, Hadzic N, Mack CL et al (2017) Guideline for the evaluation of cholestatic jaundice in infants: joint recommendations of the North American Society for Pediatric Gastroenterology, Hepatology, and Nutrition and the European Society for Pediatric Gastroenterology, Hepatology, and Nutrition. J Pediatr Gastroenterol Nutr 64(1):154-168

8. Fischler B, Lamireau T (2014) Cholestasis in the newborn and infant. Clin Res Hepatol Gastroenterol 38(3):263-267

9. Betalli P, Davenport M. Biliary atresia and other congenital disorders of the extrahepatic biliary tree. Pediatric Hepatology and Liver Transplantation. Cham: Springer; 2019. p. 129-144

10. Wada H, Muraji T, Yokoi A, Okamoto T, Sato S, Takamizawa S et al (2007) Insignificant seasonal and geographical variation in incidence of biliary atresia in Japan: a regional survey of over 20 years. J Pediatr Surg 42(12): 2090-2092

11. Chardot C, Carton M, Spire-Bendelac N, Le Pommelet C, Golmard J-L, Auvert B (1999) Epidemiology of biliary atresia in France: a national study 1986-96. J Hepatol 31(6):1006-1013

12. El-Guindi MA-S, Sira MM, Sira AM, Salem TA-H, El-Abd OL, Konsowa HA-S et al (2014) Design and validation of a diagnostic score for biliary atresia. Hepatol 61(1):116-123

13. Russo P, Magee JC, Boitnott J, Bove KE, Raghunathan T, Finegold M et al (2011) Design and validation of the biliary atresia research consortium histologic assessment system for cholestasis in infancy. Clin Gastroenterol Hepatol 9(4):357-362 e2

14. Ghazy RM, Adawy NM, Khedr MA, Tahoun MM (2018) Biliary atresia recent insight. Egypt Pediatric Assoc Gazette 66(1):1-8

15. Kasai M, Kimura S, Asakura Y, Suzuki H, Taira Y, Ohashi E (1968) Surgical treatment of biliary atresia. J Pediatr Surg 3(6):665-675

16. Huang CS, Huang CC (2010) Choledochal cysts: differences between pediatric and adult patients. J Gastrointest Surg 14(7):1105-1110

17. Rozel C, Garel L, Rypens F, Viremouneix L, Lapierre C, Décarie JC et al (2011) Imaging of biliary disorders in children. Pediatr Radiol 41(2):208-220

18. Lee SE, Jang J-Y, Lee Y-J, Choi DW, Lee WJ, Cho B-H et al (2011) Choledochal cyst and associated malignant tumors in adults: a multicenter survey in South Korea. Arch Surg 146(10):1178-1184
19. Davenport M, Basu R (2005) Under pressure: choledochal malformation manometry. J Pediatr Surg 40(2):331-335

20. Soares KC, Arnaoutakis DJ, Kamel I, Rastegar N, Anders R, Maithel S et al (2014) Choledochal cysts: presentation, clinical differentiation, and management. J Am Coll Surg 219(6):1167-1180

21. Arora A, Patidar Y, Khanna R, Alam S, Rastogi A, Negi SS (2012) Cystic biliary atresia: confounding and intriguing. J Pediatr 161(3):562

22. Jiexiong F, Minju L, Hongfeng T, Weizhong G, Shaoyong Y (2003) Clinical and pathological characteristics of cystic lesions of extrahepatic bile duct in neonates. Acta Paediatr 92(10):1183-1189

23. Verkade HJ, Bezerra JA, Davenport M, Schreiber RA, Mieli-Vergani G, Hulscher JB et al (2016) Biliary atresia and other cholestatic childhood diseases: advances and future challenges. J Hepatol 65(3):631-642

24. Caponcelli E, Knisely AS, Davenport M (2008) Cystic biliary atresia: an etiologic and prognostic subgroup. J Pediatr Surg 43(9):1619-1624

25. Lobeck IN, Sheridan R, Lovell M, Dupree P, Tiao GM, Bove KE (2017) Cystic biliary atresia and choledochal cysts are distinct histopathologic entities. Am J Surg Pathol 41(3):354-364

26. Qiao G, Li L, Li S, Tang S, Wang B, Xi H et al (2015) Laparoscopic cyst excision and Roux-Y hepaticojejunostomy for children with choledochal cysts in China: a multicenter study. Surg Endosc 29(1):140-144

27. Jun WY, Cho MJ, Han HS, Bae SH (2016) Use of omega-3 polyunsaturated fatty acids to treat inspissated bile syndrome: a case report. Pediatr Gastroenterol Hepatol Nutr 19(4):286-290

28. Davenport M, Betalli $P$, D'Antiga L, Cheeseman P, Mieli-Vergani G, Howard E (2003) The spectrum of surgical jaundice in infancy. J Pediatr Surg 38(10): $1471-1479$

29. Fitzpatrick $E$, Jardine $R$, Farrant $P$, Karani J, Davenport M, Mieli-Vergani G et al (2010) Predictive value of bile duct dimensions measured by ultrasound in neonates presenting with cholestasis. J Pediatr Gastroenterol Nutr 51(1):55-60

30. Makin E, Davenport M. Biliary atresia and other causes of surgical jaundice in infancy. Diseases of the Liver and Biliary System in Children 2017:413-429

31. Heaton N, Davenport M, Howard E (1991) Intraluminal biliary obstruction. Arch Dis Child 66(12):1395-1398

32. Berrani H, Vasies I, Cron J, Bachy B, Le Dosseur P, Mouterde O (2015) Association of $\mathrm{N}$-acetylcysteine and glucagon during percutaneous cholangiography in the treatment of inspissated bile syndrome. Arch Pediatr 22(3):300-302

33. Murphy JT, Koral K, Soeken T, Megison S (2013) Complex spontaneous bile duct perforation: an alternative approach to standard porta hepatis drainage therapy. J Pediatr Surg 48(4):893-898

34. Barnes BH, Narkewicz MR, Sokol RJ (2006) Spontaneous perforation of the bile duct in a toddler: the role of endoscopic retrograde cholangiopancreatography in diagnosis and therapy. J Pediatr Gastroenterol Nutr 43(5):695-697

35. Davenport M, Heaton N, Howard E (1991) Spontaneous perforation of the bile duct in infants. Br J Surg 78(9):1068-1070

36. Gobbi D, Leon FF, Gasparella P, Gamba P, Betalli P (2011) Conservative treatment of spontaneous biliary perforation. Pediatr Int 53(4):594-595

37. Kasat L, Borwankar S, Jain M, Naregal A (2001) Spontaneous perforation of the extrahepatic bile duct in an infant. Pediatr Surg Int 17(5-6):463-464

38. Chardot C, Iskandarani F, De Dreuzy O, Duquesne B, Pariente D, Bernard O et al (1996) Spontaneous perforation of the biliary tract in infancy: a series of 11 cases. Eur J Pediatr Surg 6(06):341-346

39. Livesey E, Davenport M (2008) Spontaneous perforation of the biliary tract and portal vein thrombosis in infancy. Pediatr Surg Int 24(3):357-359

40. Ledesma-Ramírez S (2017) Idiopathic neonatal hepatitis. Revista Mexicana de Pediatría 83(6):208-214

41. Joob B, Wiwanitkit $V$ (2017) Anti-smooth muscle antibodies and liver enzymes in differentiation of extrahepatic biliary atresia and idiopathic neonatal hepatitis: concern in laboratory medicine view. Afr J Paediatr Surg 14(3):60

42. Elferink RO (2003) Cholestasis. Gut 52(suppl 2):ii42-iii8

43. Rosenthal P (2001) Neonatal hepatitis and congenital infections. Liver Disease Children. 2:239-252

44. Carvalho E, Ivantes CAP, Bezerra JA (2007) Extrahepatic biliary atresia: current concepts and future directions. J Pediatr 83(2):105-120

45. Sira M, Sira A, Elhenawy I, Khalil F (2016) Prevalence of serological markers of TORCH infections in biliary atresia and other neonatal cholestatic disorders. Peertechz J Pediatr Ther 2(1):013-017 
46. Kaczor MP, Sanak M, Szczeklik A (2007) Rapid and inexpensive detection of a1-antitrypsin deficiency-related alleles $S$ and $Z$ by a real-time polymerase chain reaction suitable for a large-scale population-based screening. J Mol Diagn 9(1):99-104

47. Campbell KM, Arya G, Ryckman FC, Alonso M, Tiao G, Balistreri WF et al (2007) High prevalence of a-1-antitrypsin heterozygosity in children with chronic liver disease. J Pediatr Gastroenterol Nutr 44(1):99-103

48. Perlmutter DH, Brodsky JL, Balistreri WF, Trapnell BC (2007) Molecular pathogenesis of alpha-1-antitrypsin deficiency-associated liver disease: a meeting review. Hepatology. 45(5):1313-1323

49. Luisetti M, Seersholm N (2004) a1-Antitrypsin deficiency. 1: epidemiology of a1-antitrypsin deficiency. Thorax. 59(2):164-169

50. Kalsheker N (2009) a1-Antitrypsin deficiency: best clinical practice. J Clin Pathol 62(10):865-869

51. de Serres FJ (2003) Alpha-1 antitrypsin deficiency is not a rare disease but a disease that is rarely diagnosed. Environ Health Perspect 111(16):1851

52. Yachha SK, Srivastava A (2010) Alpha-1 antitrypsin deficiency related liver disease: is it worth a search in India? Indian Pediatr 47(12):1011-1012

53. Regev A, Guaqueta C, Molina EG, Conrad A, Mishra V, Brantly ML et al (2006) Does the heterozygous state of alpha- 1 antitrypsin deficiency have a role in chronic liver diseases? Interim results of a large case-control study. J Pediatr Gastroenterol Nutr 43(1):S30-SS5

54. Calderon FR, Phansalkar AR, Crockett DK, Miller M, Mao R (2007) Mutation database for the galactose-1-phosphate uridyltransferase (GALT) gene. Hum Mutat 28(10):939-943

55. Berry G, Nissim I, Gibson J, Mazur A, Lin Z, Elsas L et al (1997) Quantitative assessment of whole body galactose metabolism in galactosemic patients. Eur J Pediatr 156(1):S43-SS9

56. Coss K, Byrne J, Coman D, Adamczyk B, Abrahams J, Saldova R et al (2012) IgG N-glycans as potential biomarkers for determining galactose tolerance in Classical Galactosaemia. Mol Genet Metab 105(2):212-220

57. Waisbren SE, Potter NL, Gordon CM, Green RC, Greenstein P, Gubbels CS et al (2012) The adult galactosemic phenotype. J Inherit Metab Dis 35(2):279-286

58. Saudubray J-M, Berghe G, Walter JH (2012) Inborn metabolic diseases: Springer

59. Ammoury RF, Ghishan FK (2014) Inborn errors of carbohydrate metabolism. Liver Disease Children 435, 61-147

60. Bosch AM (2006) Classical galactosaemia revisited. J Inherit Metab Dis 29(4): 516-525

61. Berry GT (2008) Galactosemia and amenorrhea in the adolescent. Ann N Y Acad Sci 1135(1):112-117

62. Welling L, Bernstein LE, Berry GT, Burlina AB, Eyskens F, Gautschi M et al (2017) International clinical guideline for the management of classical galactosemia: diagnosis, treatment, and follow-up. J Inherit Metab Dis 40(2):171-176

63. Chen J, Yager CT, Reynolds RA, Segal S (2002) Identification of galactitol and galactonate in red blood cells by gas chromatography/mass spectrometry. Clin Chim Acta 322(1-2):37-41

64. Lindhout M, Rubio-Gozalbo ME, Bakker JA, Bierau J (2010) Direct nonradioactive assay of galactose-1-phosphate: uridyltransferase activity using high performance liquid chromatography. Clin Chim Acta 411(13-14):980-983

65. Coelho Al, Lourenço S, Trabuco M, Silva MJ, Oliveira A, Gaspar A et al (2015) Functional correction by antisense therapy of a splicing mutation in the GALT gene. Eur J Hum Genet 23(4):500

66. Bosch A, Maurice-Stam H, Wijburg F, Grootenhuis M (2009) Remarkable differences: the course of life of young adults with galactosaemia and PKU. J Inherit Metab Dis 32(6):706

67. Hoffmann B, Wendel U, Schweitzer-Krantz S (2011) Cross-sectional analysis of speech and cognitive performance in 32 patients with classic galactosemia. J Inherit Metab Dis 34(2):421-427

68. Coelho Al, Rubio-Gozalbo ME, Vicente JB, Rivera I (2017) Sweet and sour: an update on classic galactosemia. J Inherit Metab Dis 40(3):325-342

69. Berry GT (1995) The role of polyols in the pathophysiology of hypergalactosemia. Eur J Pediatr 154(2):S53-S64

70. Mitchell G, Grompe M, Lambert M, Tanguay R (2001) The metabolic and molecular bases of inherited disease

71. Nakamura K, Tanaka Y, Mitsubuchi H, Endo F (2007) Animal models of tyrosinemia. J Nutr 137(6):1556S-1560S

72. Tomoeda K, Awata H, Matsuura T, Matsuda I, Ploechl E, Milovac T et al (2000) Mutations in the 4-hydroxyphenylpyruvic acid dioxygenase gene are responsible for tyrosinemia type III and hawkinsinuria. Mol Genet Metab 71(3):506-510
73. Chinsky JM, Singh R, Ficicioglu C, van Karnebeek CD, Grompe M, Mitchell G, et al. Diagnosis and treatment of tyrosinemia type I: a US and Canadian consensus group review and recommendations. Genet Med. 2017;19(12):1-16.

74. Nakamura K, Matsumoto S, Mitsubuchi H, Endo F (2015) Diagnosis and treatment of hereditary tyrosinemia in Japan. Pediatr Int 57(1):37-40

75. Mitchell G, Larochelle J, Lambert M, Michaud J, Grenier A, Ogier $\mathrm{H}$ et al (1990) Neurologic crises in hereditary tyrosinemia. N Engl J Med 322(7): 432-437

76. Schady DA, Roy A, Finegold MJ (2015) Liver tumors in children with metabolic disorders. Transl Pediatr 4(4):290

77. Castilloux J, Laberge A-M, Martin SR, Lallier M, Marchand V (2007) "Silent" tyrosinemia presenting as hepatocellular carcinoma in a 10-year-old girl. J Pediatr Gastroenterol Nutr 44(3):375-377

78. De Jesús VR, Adam BW, Mandel D, Cuthbert CD, Matern D (2014) Succinylacetone as primary marker to detect tyrosinemia type I in newborns and its measurement by newborn screening programs. Mol Genet Metab 113(1):67-75

79. King LS, Trahms C, Scott CR (2017) Tyrosinemia type I

80. Geppert J, Stinton C, Freeman K, Fraser H, Clarke A, Johnson S et al (2017) Evaluation of pre-symptomatic nitisinone treatment on long-term outcomes in Tyrosinemia type 1 patients: a systematic review. Orphanet J Rare Dis. 12(1):154

81. Mohan N, McKiernan P, Kelly D, Preece M, Green A, Buckels J et al (1999) Indications and outcome of liver transplantation in tyrosinaemia type 1. Eur J Pediatr 158(2):S049-SS54

82. Arnon R, Annunziato R, Miloh T, Wasserstein M, Sogawa $H$, Wilson $M$ et al (2011) Liver transplantation for hereditary tyrosinemia type I: analysis of the UNOS database. Pediatr Transplant 15(4):400-405

83. Treepongkaruna $S$, Jitraruch $S$, Kodcharin $P$, Charoenpipop D, Suwannarat $P$, Pienvichit P et al (2012) Neonatal intrahepatic cholestasis caused by citrin deficiency: prevalence and SLC25A13 mutations among Thai infants. BMC Gastroenterol 12(1):141

84. Ohura T, Kobayashi K, Tazawa Y, Abukawa D, Sakamoto O, Tsuchiya S et al (2007) Clinical pictures of 75 patients with neonatal intrahepatic cholestasis caused by citrin deficiency (NICCD). J Inherit Metab Dis 30(2):139-144

85. Kimura A, Kage M, Nagata I, Mushiake S, Ohura T, Tazawa Y et al (2010) Histological findings in the livers of patients with neonatal intrahepatic cholestasis caused by citrin deficiency. Hepatol Res 40(3):295-303

86. Song Y-Z, Li B-X, Chen F-P, Liu S-R, Sheng J-S, Ushikai M et al (2009) Neonatal intrahepatic cholestasis caused by citrin deficiency: clinical and laboratory investigation of 13 subjects in mainland of China. Dig Liver Dis 41(9):683-689

87. Tokuhara D, lijima M, Tamamori A, Ohura T, Takaya J, Maisawa S et al (2007) Novel diagnostic approach to citrin deficiency: analysis of citrin protein in lymphocytes. Mol Genet Metab 90(1):30-36

88. O'Sullivan BP, Freedman SD (2009) Cystic fibrosis. Lancet. 373(9678): 1891-1904

89. Eminoglu TF, Polat E, Gökçe S, Ezgü FS, Senel S, Apaydin S (2013) Cystic fibrosis presenting with neonatal cholestasis simulating biliary atresia in a patient with a novel mutation. Indian J Pediatr 80(6):502-504

90. Kharrazi M, Yang J, Bishop T, Lessing S, Young S, Graham S et al (2015) Newborn screening for cystic fibrosis in California. Pediatrics. 136(6): 1062-1072

91. Leeuwen L, Magoffin AK, Fitzgerald DA, Cipolli M, Gaskin KJ. Cholestasis and meconium ileus in infants with cystic fibrosis and their clinical outcomes. Arch Dis Child. 2014;99(5):443-7.

92. Parisi GF, Di Dio G, Franzonello C, Gennaro A, Rotolo N, Lionetti E, et al. Liver disease in cystic fibrosis: an update. Hepat Mon. 2013;13(8)

93. Greenholz SK, Krishnadasan B, Marr C, Cannon R (1997) Biliary obstruction in infants with cystic fibrosis requiring Kasai portoenterostomy. J Pediatr Surg 32(2):175-180

94. Molmenti EP, Squires RH, Nagata D, Roden JS, Molmenti H, Fasola CG et al (2003) Liver transplantation for cholestasis associated with cystic fibrosis in the pediatric population. Pediatr Transplant 7(2):93-97

95. Hollander FM, de Roos NM, Heijerman HG (2017) The optimal approach to nutrition and cystic fibrosis: latest evidence and recommendations. Curr Opin Pulm Med 23(6):556-561

96. Kobelska-Dubiel N, Klincewicz B, Cichy W (2014) Liver disease in cystic fibrosis. Prz Gastroenterol 9(3):136-141

97. Setchell KD, Heubi JE (2006) Defects in bile acid biosynthesis-diagnosis and treatment. J Pediatr Gastroenterol Nutr 43(1):S17-S22 
98. Lane E, Murray KF (2017) Neonatal cholestasis. Pediatr Clin 64(3):621-639

99. Oda T, Elkahloun AG, Pike BL, Okajima K, Krantz ID, Genin A et al (1997) Mutations in the human Jagged 1 gene are responsible for Alagille syndrome. Nat Genet 16(3):235

100. McDaniell R, Warthen DM, Sanchez-Lara PA, Pai A, Krantz ID, Piccoli DA et al (2006) NOTCH2 mutations cause Alagille syndrome, a heterogeneous disorder of the notch signaling pathway. Am J Hum Genet 79(1):169-173

101. Turnpenny PD, Ellard S (2012) Alagille syndrome: pathogenesis, diagnosis and management. Eur J Hum Genet 20(3):251

102. Danks D, Campbell P, Jack I, Rogers J, Smith A (1977) Studies of the aetiology of neonatal hepatitis and biliary atresia. Arch Dis Child 52(5):360-367

103. Saleh M, Kamath BM, Chitayat D (2016) Alagille syndrome: clinical perspectives. Appl Clin Genet 9:75-82

104. Dhorne-Pollet S, Deleuze J, Hadchouel M, Bonaiti-Pellie C (1994) Segregation analysis of Alagille syndrome. J Med Genet 31(6):453-457

105. Mattei P, von Allmen D, Piccoli D, Rand E (2006) Relief of intractable pruritis in Alagille syndrome by partial external biliary diversion. J Pediatr Surg 41(1):104-107

106. Kamath BM, Schwarz KB, Hadžic N (2010) Alagille syndrome and liver transplantation. J Pediatr Gastroenterol Nutr 50(1):11-15

107. Amer S, Hajira A (2014) A comprehensive review of progressive familial intrahepatic cholestasis (PFIC): genetic disorders of hepatocanalicular transporters. Gastroenterology Res 7(2):39

108. Schwab P, Racsa P, Rascati K, Mourer M, Meah Y, Worley K (2019) A retrospective database study comparing diabetes-related medication adherence and health outcomes for mail-order versus community pharmacy. J Manag Care Spec Pharm 25(3):332-340

109. Davit-Spraul A, Gonzales E, Baussan C, Jacquemin E (2009) Progressive familial intrahepatic cholestasis. Orphanet J Rare Dis 4(1):1

110. Kullak-Ublick GA, Beuers U, Paumgartner G (2000) Hepatobiliary transport. J Hepatol 32:3-18

111. Zhou Y, Zhang J (2014) Arthrogryposis-renal dysfunction-cholestasis (ARC) syndrome: from molecular genetics to clinical features. Ital J Pediatr 40(1):77

112. Taha D, Khider A, Cullinane AR, Gissen P (2007) A novel VPS33B mutation in an ARC syndrome patient presenting with osteopenia and fractures at birth. Am J Med Genet 143(23):2835-2837

113. Abdullah MA, Al-Hasnan Z, Okamoto E, Abomelha AM (2000) Arthrogryposis, renal dysfunction and cholestasis syndrome. Saudi Med J 21(3):297-299

114. Malaki M, Mandana R, Ghaffari S (2012) ARC syndrome with complex renal problems: nephrocalcinosis, proximal and hyperkalemic distal RTA and nephrogenic diabetes insipidus. Saudi J Kidney Dis Transpl 23(4):804

115. Bull LN, Mahmoodi V, Baker AJ, Jones R, Strautnieks SS, Thompson RJ et al (2006) VPS33B mutation with ichthyosis, cholestasis, and renal dysfunction but without arthrogryposis: incomplete ARC syndrome phenotype. J Pediatr 148(2):269-271

116. Jang JY, Kim KM, Kim G-H, Yu E, Lee J-J, Park YS et al (2009) Clinical characteristics and VPS33B mutations in patients with ARC syndrome. J Pediatr Gastroenterol Nutr 48(3):348-354

117. Jang WY, Cho T-J, Bae JY, Jung HW, Ko JS, Park MS et al (2011) Orthopaedic manifestations of arthrogryposis-renal dysfunction-cholestasis syndrome. J Pediatr Orthop 31(1):107-112

118. Kirk JM (2008) Neonatal jaundice: a critical review of the role and practice of bilirubin analysis. Ann Clin Biochem 45(5):452-462

119. Wright K, Ernst KD, Gaylord MS, Dawson JP, Burnette TM (2003) Increased incidence of parenteral nutrition-associated cholestasis with aminosyn PF compared to trophamine. J Perinatol 23(6):444

120. Albers MJ, de Gast-Bakker D-AH, van Dam NA, Madern GC, Tibboel D (2002) Male sex predisposes the newborn surgical patient to parenteral nutritionassociated cholestasis and to sepsis. Arch Surg 137(7):789-793

121. Whitfield P, Iyer K (1998) The role of phytosterols in the pathogenesis of liver complications of pediatric parenteral nutrition. Nutrition. 14(1):158-164

122. Sondheimer JM, Asturias E, Cadnapaphornchai M (1998) Infection and cholestasis in neonates with intestinal resection and long-term parenteral nutrition. J Pediatr Gastroenterol Nutr 27(2):131-137

123. Buchman AL, lyer K, Fryer J (2006) Parenteral nutrition-associated liver disease and the role for isolated intestine and intestine/liver transplantation. Hepatology. 43(1):9-19

124. Zambrano E, El-Hennawy M, Ehrenkranz RA, Zelterman D, Reyes-Múgica M (2004) Total parenteral nutrition induced liver pathology: an autopsy series of 24 newborn cases. Pediatr Dev Pathol 7(5):425-432
125. Chen H-L, Chen H-L, Liu Y-J, Feng C-H, Wu C-Y, Shyu M-K et al (2005) Developmental expression of canalicular transporter genes in human liver. Hepatol 43(3):472-477

126. Reiner $\breve{Z}$, Guardamagna O, Nair D, Soran H, Hovingh K, Bertolini S et al (2014) Lysosomal acid lipase deficiency-an under-recognized cause of dyslipidaemia and liver dysfunction. Atherosclerosis. 235(1):21-30

127. Tinsa F, Romdhane MB, Boudabous H, Hadj IB, Brini I, Tebib N, et al. A Novel Mutation C. 153 C> A in a Tunisian Girl With Wolman Disease and Unusual Presentation: Hemophagocytic Lymphohistiocytosis. J Pediatr Hematol Oncol. 2019;41(3):e193-e196.

128. Porto AF (2014) Lysosomal acid lipase deficiency: diagnosis and treatment of Wolman and cholesteryl ester storage diseases. Pediatr Endocrinol Rev: PER 12:125-132

129. Bernstein DL, Hülkova H, Bialer MG, Desnick RJ (2013) Cholesteryl ester storage disease: review of the findings in 135 reported patients with an underdiagnosed disease. J Hepatol 58(6):1230-1243

130. Ghosh A, Cooper J, Church H, Jones SA, Wu H (2017) Plasma oxysterols as a putative biomarker for infantile onset lysosomal acid lipase deficiency (Wolman disease). Mol Genet Metab 120(1):S52-SS3

131. Muntoni S, Wiebusch H, Funke H, Ros E, Seedorf U, Assmann G (1995) Homozygosity for a splice junction mutation in exon 8 of the gene encoding lysosomal acid lipase in a Spanish kindred with cholesterol ester storage disease (CESD). Hum Genet 95(5):491-494

132. Feranchak AP, Sokol R (2007) Medical and nutritional management of cholestasis in infants and children. Liver Dis Children 3:190-231

133. Venigalla S, Gourley GR, editors. Neonatal cholestasis. Semin Perinatol; 2004; 28(5):348-55. Elsevier

134. Sokol RJ, Shepherd RW, Superina R, Bezerra JA, Robuck P, Hoofnagle JH (2007) Screening and outcomes in biliary atresia: summary of a National Institutes of Health workshop. Hepatology. 46(2):566-581

135. Bhatia V, Bavdekar A (2013) Management of acute liver failure in infants and children: consensus statement of the pediatric gastroenterology chapter, Indian academy of pediatrics. Indian Pediatr 50(5):477-482

136. Sharma D, Shah UH, Sibal A, Chowdhary SK (2010) Cholecystoappendicostomy for progressive familial intrahepatic cholestasis. Indian Pediatr 47(7):626-628

\section{Publisher's Note}

Springer Nature remains neutral with regard to jurisdictional claims in published maps and institutional affiliations.

\section{Submit your manuscript to a SpringerOpen ${ }^{\circ}$ journal and benefit from:}

- Convenient online submission

- Rigorous peer review

- Open access: articles freely available online

- High visibility within the field

- Retaining the copyright to your article

Submit your next manuscript at $>$ springeropen.com 